\title{
PARA UMA AVALIAÇÃo EMANCIPADORA: A MEDIAÇÃO PELO DIÁLOGO
}

\author{
PARA UNA EVALUACIÓN EMANCIPADORA: LA MEDIACIÓN POR EL DIÁLOGO
}

FOR AN EMANCIPATORY EVALUATION: MEDIATION THROUGH DIALOGUE

\author{
Teresa de Jesus Correia Paulino dos SANTOS ${ }^{1}$ \\ Maria Palmira ALVES ${ }^{2}$
}

RESUMO: Desenvolver uma educação libertadora é reconhecer que o conhecimento é um processo de descoberta coletiva, mediada pelo diálogo entre professor e aluno. Educar numa perspetiva libertadora pressupõe atender à singularidade de cada aluno, num processo de desenvolvimento curricular em que a avaliação assume uma função formadora. Apresentamos um estudo, de natureza qualitativa, desenvolvido num agrupamento de escolas, localizado na zona Norte de Portugal, tendo como principais objetivos avaliar os efeitos de um projeto de combate ao insucesso escolar, no ensino básico; e conhecer as dinâmicas que, na opinião dos professores, contribuíram para o sucesso do projeto. O instrumento de recolha de dados foi a entrevista semiestruturada, tendo sido realizadas a 10 professores que desempenharam cargos de coordenação durante a duração do projeto. Os dados foram analisados com recurso à análise de conteúdo. Os resultados salientam, o sucesso do projeto deveu-se, sobretudo, às dinâmicas de cooperação dos encarregados de educação com a escola. Revelou-se importante consolidar a flexibilização curricular, que permita atender ao aluno de forma a que ocupe a centralidade no processo de desenvolvimento do currículo; e fomentar o diálogo entre professor e aluno, nomeadamente, através de mecanismos de feedback, traçando um percurso de avaliação reflexivo e emancipador.

PALAVRAS-CHAVE: Projeto. Avaliação. Ensino básico.

RESUMEN: Desarrollar una educación libertadora es reconocer que el conocimiento es un proceso de descubierta colectiva, mediada por el diálogo entre profesor y alumno. Educar desde una perspectiva libertadora presupone atender a la singularidad de cada alumno, en un proceso de desarrollo curricular en que la evaluación asume una función formadora. Presentamos un estudio, de naturaleza cualitativa, desarrollado en un agrupamiento de escuelas, ubicado en la zona Norte de Portugal, teniendo como principales objetivos evaluar los efectos de un proyecto de combate al fracaso escolar, en la enseñanza básica; y conocer las dinámicas que, en la opinión de los profesores, contribuyeron para el suceso del proyecto. El instrumento de recopilación de datos fue la entrevista semiestructurada, y se han realizado a 10 profesores que desempeñaron cargos de coordinación durante la duración del proyecto. Los datos fueron analizados con recurso al análisis de contenido. Los resultados señalan, el suceso del proyecto sucedió, sobre todo, a las dinámicas de cooperación de los encargados de educación con la escuela. Se reveló importante consolidar la flexibilización curricular,

${ }^{1}$ Universidade do Minho (UM), Braga - Portugal. CIEC - Centro de Investigação em Estudos da Criança. ORCID: https://orcid.org/0000-0002-7165-9051.E-mail: tjcps@ sapo.pt

${ }^{2}$ Universidade do Minho (UM), Braga - Portugal. CIEC - Centro de Investigação em Estudos da Criança. ORCID: https://orcid.org/0000-0002-3108-744X. E-mail: palves@ie.uminho.pt 
que permitía atenderle al alumno de forma que ocupara la centralidad en el proceso de desarrollo del currículo; y fomentar el diálogo entre profesor y alumno, especialmente, desde mecanismos de feedback, planteando un camino de evaluación reflexivo y emancipador.

PALABRAS CLAVE: Proyecto. Evaluación. Enseñanza básica.

ABSTRACT: To develop a liberating education is to recognize that knowledge is a process of collective discovery, mediated by dialogue between teacher and student. Educating in a liberating perspective presupposes attending the singularity of each student, in a process of curricular development in which the evaluation assumes a formative function. We present a study, of a qualitative nature, developed in a group of schools, located in the North of Portugal, with the main objectives of evaluating the effects of a project to combat school failure, in basic education; and to know the dynamics that, in the opinion of the teachers, contributed to the success of the project. The instrument of data collection was the semistructured interview, which was carried out with 10 teachers who held coordination positions during the duration of the project. The data were analyzed using content analysis. The results emphasize that the success of the project was mainly due to the cooperation dynamics of the education officers with the school. It has proved important to consolidate the flexibility of the curriculum, which allows the student to occupy the centrality in the process of curriculum development; and to encourage dialogue between teacher and student, particularly through feedback mechanisms, tracing a path of reflective and emancipatory evaluation.

KEYWORDS: Project. Evaluation. Elementary school.

\section{Uma aprendizagem centrada no aluno}

\section{Contributos legislativos}

A Educação Cidadã, paradigma que sustenta a conceção dos Direitos Humanos na educação, é sustentada por "uma educação que se politiza e politiza o mundo e as pessoas" e que "nos convoca e incentiva a tomar decisões a partir daquilo que existe de melhor nas mulheres e nos homens" (MACHADO, 2016). É uma condição de cidadania epistemológica equilibrada de todos os saberes necessários à condição humana.

O papel formativo da escola é contemplado na diversidade do contexto globalizado por saberes selecionados por uma sociedade e os seus valores serão transmitidos e construídos mediante ações educativas. A escola de todos e para todos, não é apenas o acesso à escola, mas o acesso aos bens culturais da sociedade: conhecimentos, linguagens, expressões artísticas, práticas sociais e morais, enfim, o direito a um legado de realizações históricas às quais conferimos valor e das quais esperamos que as novas gerações se apoderem.

A legislação relativa à organização e gestão dos currículos dos ensinos básico e secundário, da avaliação do ensino e das aprendizagens e do processo de desenvolvimento do 
currículo destes níveis de ensino, assegura a dimensão eminentemente formativa da avaliação, que deve ser integrada e indutora de melhorias no ensino e na aprendizagem.

Considerando que um modelo de avaliação é tanto mais exigente quanto mais contemple a introdução de mecanismos de maior qualidade no ensino e na aprendizagem, na medida em que fornece pistas claras para conduzir a uma melhoria progressiva das práticas a desenvolver e dos desempenhos de cada aluno, a exigência constrói-se pela diferenciação pedagógica assente numa intervenção precoce no percurso das aprendizagens.

Consciente desta situação, o governo lançou o Programa Nacional de Promoção do Sucesso Escolar, com a finalidade de promover um ensino de qualidade e combater o insucesso escolar. Este programa visa a valorização da igualdade de oportunidades e o aumento da eficiência e qualidade da escola pública e tem como principais diretrizes: o envolvimento de todos os atores sociais com impacto na comunidade educativa; a criação de dinâmicas locais de diagnóstico e intervenção, a partir do conhecimento produzido pelas escolas (oferta educativa); a promoção de práticas que permitam antecipar e prevenir o insucesso, através de uma aposta na intervenção precoce; a dinamização de um programa de formação contínua, que capacite as escolas para a reflexão sobre práticas locais e para o desenvolvimento de estratégias inovadoras e indutoras de mudança; o acompanhamento e supervisão das estratégias locais de promoção do sucesso escolar; a produção de conhecimento científico sobre o sucesso escolar e suas condicionantes; a avaliação periódica do Programa, nas suas múltiplas dimensões. A regulamentação sobre o regime de avaliação e certificação das aprendizagens desenvolvidas pelos alunos do ensino básico (Despacho normativo n. ${ }^{\circ}$ 1-F/2016) apresenta medidas de promoção do sucesso educativo, pensadas pelo professor titular de turma e por cada conselho de turma, a partir de um efetivo conhecimento das dificuldades, de acordo com as fragilidades a ultrapassar, tendo em conta as características dos alunos e as possibilidades de cada comunidade escolar. Este normativo salienta a coadjuvação em sala de aula, valorizando as experiências e as práticas colaborativas que conduzam à melhoria das práticas; o apoio ao estudo orientado para a satisfação de necessidades específicas, contribuindo para um trabalho de proximidade e acompanhamento eficaz do aluno face às dificuldades detetadas; a implementação de tutorias, visando o acompanhamento com vista à melhoria das aprendizagens e ao desenvolvimento de competências pessoais e sociais dos alunos.

Estes desafios levaram o Ministério da Educação a propor às escolas do ensino básico uma política curricular de participação voluntária " o Projeto de Autonomia e flexibilidade curricular" (Despacho n. ${ }^{\circ}$ 5908/2017), que visa a promoção de melhores aprendizagens 
indutoras do desenvolvimento de competências de nível mais elevado, assumindo a centralidade das escolas, dos seus alunos e professores, e permitindo a gestão do currículo de forma flexível e contextualizada, reconhecendo que o exercício efetivo de autonomia em educação só é plenamente garantido se o objeto dessa autonomia for o currículo. Estas medidas, com vista a atingir um perfil de base humanística, impulsionaram à definição de um perfil dos alunos à saída da escolaridade obrigatória. Trata-se de formar pessoas autónomas e responsáveis, que sejam verdadeiros cidadãos ativos.

Ainda neste alinhamento da política educativa, preconizam-se "novos desafios, decorrentes de desenvolvimento tecnológico em aceleração, tendo a escola de preparar os alunos, que serão jovens e adultos em 2030, para empregos ainda não criados, para tecnologias ainda não inventadas, para a resolução de problemas que ainda se desconhecem" (decreto-lei 55/2018). Com vista a atingir um perfil de base humanística, o currículo visa garantir que todos os alunos, independentemente da oferta educativa e formativa que frequentem, alcancem as competências definidas no Perfil dos Alunos à Saída da Escolaridade Obrigatória. O decreto lei refere uma “Abordagem multinível”, opção metodológica que permite o acesso ao currículo ajustada às potencialidades e dificuldades dos alunos, com recurso a diferentes níveis de intervenção; “ as Aprendizagens Essenciais”, conjunto comum de conhecimentos a adquirir; a "Autonomia e flexibilidade curricular", faculdade conferida à escola para gerir o currículo dos ensinos básico e secundário, partindo das matrizes curriculares-base; os "Documentos curriculares", conjunto de documentos em que estão expressos os conhecimentos a adquirir, as capacidades e atitudes a desenvolver pelos alunos, designadamente, os programas, metas, orientações, perfis profissionais; “ os Domínios de autonomia curricular" (DAC), áreas de confluência de trabalho interdisciplinar e ou de articulação curricular; a "Estratégia Nacional de Educação para a Cidadania", estratégia que visa o desenvolvimento de competências para uma cultura de democracia e aprendizagens com impacto na atitude cívica individual; as "Matrizes curriculares-base", conjunto de componentes de currículo, áreas disciplinares e disciplinas, que integram os planos curriculares de âmbito nacional, por ciclo e ano de escolaridade; o "Perfil dos Alunos à Saída da Escolaridade Obrigatória”, que está estruturado em princípios, visão e valores.

\section{Uma perspetiva integrada de avaliação: condições para o sucesso}

A avaliação das aprendizagens "tem vindo a ser ampliada em formas de avaliação formativa com a função de acompanhar todo o processo de ensino aprendizagem e contribuir 
para a melhoria contínua das aprendizagens” (ALVES; SÁ, 2014, p. 531). Esta lógica formativa tem uma vertente contínua e sistemática e fornece ao professor, ao aluno, ao encarregado de educação e aos restantes intervenientes, informação sobre o desenvolvimento do trabalho, de modo a permitir a revisão e melhoria do processo de ensino e de aprendizagem. O erro deixará de ser visto como uma lacuna, passando a ser aceite como um indicador do percurso de aprendizagem e "o feedback é importante [...] regula e controla os processos de aprendizagem, assim como para melhorar a motivação e autoestima" (FERNANDES, 2006, p. 31).

Assim, o feedback é um elemento essencial de comunicação e de interação entre o professor e o aluno, permite ao primeiro perceber as alterações que tem de fazer à sua ação de ensinar, de modo a poder ajustá-la às necessidades do aluno e potenciar uma maior consciencialização dos seus pontos fortes, assim como, a identificação dos seus pontos fracos para orientá-lo na realização de ações que diminuam as suas dificuldades. Ao aluno permite ter a noção, quer dos seus sucessos, quer da forma como ultrapassar os insucessos com que se vai defrontando ao longo do seu processo de aprendizagem. Alves, Aguiar e Oliveira (2014) acrescentam que o feedback pode ser escrito nas margens dos trabalhos, ser de natureza oral (transmitido nas aulas ou em sessões de apoio tutorial individualizado) e/ou fornecido com recurso às novas tecnologias. $\mathrm{O}$ uso de feedback adequado poderá ajudar o aluno a assumir-se como um aprendente autónomo, construindo e utilizando os seus processos metacognitivos e autoavaliando a sua aprendizagem. Assim, o aluno pode aprender com os erros cometidos, ler e refletir sobre o que fez, bem como, encontrar estratégias para não cometer os erros noutras tarefas. A implementação deste tipo de práticas no ensino abre a porta à implementação de outras formas de avaliação, que consideramos fundamentais para o sucesso dos alunos: a autoavaliação, a metacognição, a autorregulação, o desenvolvimento da autonomia e o feedback, dando ênfase ao papel do aluno, colocando-o numa posição de protagonista do processo de ensino aprendizagem. A este propósito, Lopes e Silva (2012) referem as três orientações da avaliação: avaliação para a aprendizagem; avaliação como aprendizagem e avaliação das aprendizagens. A avaliação para a aprendizagem promove a consolidação da aprendizagem e a colocação do aluno no centro de todo o processo, incluindo a autoavaliação, avaliação por pares o feedback para suporte da aprendizagem e questionamento efetivo.

A avaliação como aprendizagem enfatiza a responsabilidade dos alunos em relação à aprendizagem e à avaliação envolvendo-os no processo de auto e heteroavaliação (Lopes \& Silva, 2012). Por último, a avaliação das aprendizagens é utilizada pelos professores para fazer o julgamento sobre o desempenho em relação aos objetivos da aprendizagem e pode 
ocorrer numa unidade de ensino ou num período, sendo que esta orientação tem caráter sumativo e os testes têm sido criticados por serem tendenciosos e injustos (LOPES; SILVA, 2012).

Esta abordagem permitirá ao professor adequar as tarefas a cada situação específica pois, dado o seu caráter contínuo, ocorre em momentos diversificados (ALVES, 2004), ou seja, no início da tarefa (regulação proativa); ao longo da tarefa (regulação interativa) e após a sequência de aprendizagem (regulação retroativa) cabendo aos professores selecionar as diversas de tarefas e levar os alunos a participar ativamente, para que a avaliação esteja integrada no processo formativo.

Neste sentido, e tal como refere Simão (2008, p. 125) "os esforços para melhorar a educação exigem a melhoria das práticas de avaliação", salientando a função de regulação da avaliação, pois cada professor deve adequar a sua ação às dificuldades e necessidades que o aluno apresenta no seu processo de aprendizagem, permitindo-lhe caminhar no sentido da autorregulação, com a finalidade de ir construindo um sistema pessoal para aprender, ou seja, tanto quanto possível, que aprenda a aprender. O processo de aprendizagem assenta, fundamentalmente, na relação estabelecida entre o aprendente e o saber, sendo que o professor desempenha um papel passivo (PINTO; SANTOS, 2006, p. 37). Os alunos não adquirem todos "ao mesmo tempo as mesmas aprendizagens, pelo que, para prevenir o fracasso escolar, para não agravar ainda mais as desigualdades iniciais, é preciso diferenciar o ensino e dedicar mais tempo e mais recursos para ajudar os menos favorecidos" (PERRENOUD, 2001, p. 49). Embora a escola seja a principal responsável pelo sucesso escolar dos alunos, ela não pode responsabilizar-se sozinha, são vários os fatores que explicam o sucesso e o insucesso dos alunos, pois é necessário responsabilizar e envolver os pais na educação dos seus filhos (VIEIRA, 2003). A escola, as famílias, o estado, ou o sistema económico e o próprio aluno são responsáveis pelo insucesso (MARCHESI; GIL, 2004). Também o currículo, em sentido lato, corresponde ao corpo de aprendizagens (conhecimentos de vários níveis e tipos, valores, técnicas, outros) que cada sociedade considera necessários para sobreviver e que cada um dos seus membros precisa de se apropriar para nela se integrar (ROLDÃO, 2013). 


\section{Opções metodológicas do estudo}

\section{Objetivos e descrição do estudo e dos intervenientes no estudo}

A perspetiva teórica e legislativa que acabámos de apresentar conduziu-nos aos objetivos do estudo, a saber: - avaliar os efeitos do projeto do agrupamento para combate ao insucesso escolar, no ensino básico; e conhecer as dinâmicas que, na opinião dos professores, contribuíram para o sucesso do projeto.

Para a sua consecução, optámos por um estudo de caso que, tal como salienta Bell (2002, p. 23), “ permite ao investigador a possibilidade de se concentrar num caso específico ou situação", justificando uma abordagem metodológica qualitativa.

O Agrupamento de Escolas abrange três estabelecimentos de ensino do pré-escolar ao $3^{\text {o }}$ ciclo do Ensino Básico, com 754 alunos, 38 turmas e 81 professores. Inquirimos, por entrevista, 10 professores, que caraterizamos na tabela 1.

Tabela 1 - Perfil dos entrevistados

\begin{tabular}{|c|c|c|c|c|c|}
\hline Código & Género & $\begin{array}{c}\text { Anos } \\
\text { docência }\end{array}$ & $\begin{array}{l}\text { Nível de ensino } \\
\text { que leciona }\end{array}$ & Disciplina/ leciona & Cargo(s) Desempenhado(s) \\
\hline P1 & M & 20 & $2^{\circ}$ Ciclo ( $5^{\circ}$ e $6^{\circ}$ anos $)$ & Matemática & $\begin{array}{l}\text { Coordenador de } 5^{\circ} \\
\text { ano }\end{array}$ \\
\hline $\mathrm{P} 2$ & $\mathrm{~F}$ & 22 & $3^{\circ}$ Ciclo (7. ${ }^{\circ}$ e $8 .^{\circ}$ anos $)$ & Físico-química & $\begin{array}{l}\text { Coordenadora dos Diretores } \\
\text { Turma }\end{array}$ \\
\hline P3 & $\mathrm{F}$ & 26 & $3^{\circ}$ Ciclo $\left(7^{\circ}\right.$ e $8 .^{\circ}$ anos $)$ & Português & Diretora de Turma \\
\hline P4 & M & 24 & $3^{\circ}$ Ciclo $\left(7^{\circ}\right.$ e $8^{\circ}$ anos $)$ & Educação Visual & Coordenador de $7^{\circ}$ ano \\
\hline P5 & $\mathrm{F}$ & 30 & $2^{\circ}$ Ciclo $\left(5^{\circ}\right.$ e $6^{\circ}$ anos $)$ & Ciências & $\begin{array}{l}\text { Coordenadora de Educação para a } \\
\text { Saúde }\end{array}$ \\
\hline P6 & $\mathrm{F}$ & 20 & $3^{\circ}$ Ciclo $\left(8^{\circ}\right.$ e $9^{\circ}$ anos $)$ & Inglês & Diretora de Turma \\
\hline P7 & M & 38 & $2^{\circ}$ Ciclo $\left(6^{\circ}\right.$ ano $)$ & Educação tecnológica & $\begin{array}{l}\text { Coordenador de Expressões e } \\
\text { Tecnologias }\end{array}$ \\
\hline P8 & M & 36 & Cursos EFA & EFA & Coordenador do Centro Qualifica. \\
\hline P9 & M & 5 & $3^{\circ}$ Ciclo $\left(8^{\circ}\right.$ e $9^{\circ}$ anos $)$ & Geografia & Diretor de Turma \\
\hline P10 & M & 25 & $3^{\circ}$ Ciclo ( $9^{\circ}$ ano $)$ & Português & $\begin{array}{l}\text { Coordenador de Línguas e } \\
\text { Literatura }\end{array}$ \\
\hline
\end{tabular}

Fonte: elaborada pelos autores

Os professores entrevistados têm entre 20 e 38 anos de serviço docente, sendo que apenas um leciona há 5 anos; $40 \%$ são do sexo feminino e $60 \%$ são do sexo masculino. Relativamente ao nível de ensino, três entrevistados lecionam no $2 .^{\circ}$ Ciclo $\left(5 .^{\circ}\right.$ e $6 .^{\circ}$ anos de escolaridade), seis lecionam no $3^{\circ}$ Ciclo $\left(7 .^{\circ}, 8 .^{\circ}\right.$ e $9 .^{\circ}$ anos de escolaridade) e um leciona nos cursos de Educação e Formação de Adultos (EFA). 
Quanto aos cargos desempenhados, os entrevistados exercem as seguintes funções de liderança no agrupamento: dois coordenadores de departamento; dois coordenadores de ano; uma coordenadora dos diretores de turma; um coordenador do centro qualifica; uma coordenadora de educação para a saúde e três diretores de turma.

\section{Entrevistas}

A realização de entrevistas é um dos métodos apropriados para utilizar num estudo de caso sobre as instituições educativas, pois permite obter informações pertinentes, que não podem ser encontradas em registos ou fontes documentais. $\mathrm{O}$ recurso à técnica das entrevistas semiestruturadas permitiu ao investigador "desenvolver intuitivamente uma ideia sobre a maneira como os sujeitos interpretam aspetos do mundo" (BOGDAN; BIKLEN, 1994, p. 134). Deste modo, os dados foram recolhidos com recurso a entrevistas semiestruturadas. Estas, depois de observadas todas as normas éticas, foram gravadas, transcritas e, posteriormente, submetidas a análise de conteúdo ou análise temática (Bardin, 2009, p. 198), que consiste na "operação de classificação de elementos constitutivos de um conjunto por diferenciação e, seguidamente, por reagrupamento segundo o género (analogia)" (BARDIN, 2009, p. 145).

Foi assegurada a proteção da identidade dos sujeitos, tendo sido atribuído o código (P) para professor, seguido de número (de 1 a 10).

Procedemos à leitura integral das entrevistas e, seguidamente, a uma leitura mais aprofundada, num constante viajar por cada um dos discursos, que nos abriu o caminho para a identificação de dimensões, sendo a primeira: "Perceções sobre Sucesso / insucesso", que subdividimos em categorias e subcategorias, de acordo com as unidades de registo. Neste texto, apresentamos os resultados desta dimensão, as perceções dos professores sobre sucesso/insucesso, cuja estrutura de análise apresentamos na tabela 2. 
Tabela 2 - Dimensão, categorias de análise e subcategorias

\begin{tabular}{|c|c|c|}
\hline 1.Dimensão & Categorias & Subcategorias \\
\hline \multirow{3}{*}{$\begin{array}{c}\text { Perceções sobre } \\
\text { Sucesso / insucesso }\end{array}$} & 1.1. Perspetivas sobre sucesso & $\begin{array}{l}\text { 1. Significado de sucesso/insucesso } \\
\text { 2. Fatores de sucesso dos alunos }\end{array}$ \\
\hline & 1.2. Ambiente de aprendizagem & $\begin{array}{l}\text { 1.Motivação intrínseca e extrínseca. } \\
\text { 2. Envolvimento dos alunos na } \\
\text { aprendizagem }\end{array}$ \\
\hline & 1.3 Avaliação & $\begin{array}{l}\text { 1. Funções da avaliação } \\
\text { 2. Tarefas / critérios de avaliação } \\
\text { 3. Praticas de Autoavaliação }\end{array}$ \\
\hline
\end{tabular}

Fonte: elaborada pelos autores

\section{Apresentação e análise dos resultados}

Depois de analisadas as entrevistas realizadas aos 6 professores, passamos à apresentação dos resultados sobre as suas perspetivas relativas ao sucesso escolar, triangulando as suas perspetivas com a dimensão teórica que fundamenta o presente estudo.

\section{Dimensão Perspetivas sobre Sucesso / insucesso}

Esta dimensão engloba três categorias que nos permitiram conhecer e analisar as perspetivas dos professores relativamente ao sucesso e à avaliação. Assim, a primeira categoria denomina-se "Perspetivas sobre sucesso", a segunda "Ambiente de aprendizagem" e a terceira "Avaliação" sendo cada uma delas seguidamente analisada.

\section{Perspetivas de (in)sucesso escolar}

Para os professores entrevistados ter sucesso escolar é transitar de ano e adquirir as competências previstas. O insucesso é a não consecução dos objetivos definidos para o aluno.

Os professores salientam a importância do sucesso como "Um percurso ao longo dos ciclos, sem retenções e com o conjunto vasto de conhecimentos, capacidades e atitudes" (P2); 
acrescentam que "o sucesso não se baseia só nas notas, o aluno deve adquirir todas as competências necessárias para um dia mais tarde ser um bom profissional" (P3). Um professor considera que os alunos" partem de situações diferentes e uns progridem mais do que outros, o que não quer dizer que aqueles que progridem mais atingem as suas competências definidas para a disciplina" (P5). Referem, ainda, ser muito importante " ter espírito critico, ter opinião própria, sentirem-se bem na escola e não sentirem que a escola é uma obrigação “(P6).

$\mathrm{Na}$ opinião dos professores entrevistados, o insucesso remete-nos para os processos de inadaptação à escola "não conseguir acompanhar as exigências escolares ainda que beneficiem de todo o tipo de apoio” (P4 ). É “evidente que nós queremos que todos atinjam as mesmas competências e nem sempre é possível, pois alguns não conseguem no mesmo tempo e vão fícando para trás"(P5); "Penso que a obsessão pelos números torna o conceito de insucesso muito redutor. Um aluno pode ter tido classificações baixas ao longo do seu período escolar e, ainda assim, ter adquirido competências para a vida"(P1).

Noutro estudo, (SANTOS; ALVES, 2016) concluíram que os professores consideram que o sucesso escolar advém do esforço, da dedicação e do comportamento; a avaliação controla o estudo, obriga a estudar e diagnostica o que os alunos sabem. As estratégias de abordagem dos conteúdos e os conteúdos não motivam os alunos. Consideram que o estudo é muito importante para o sucesso.

\section{Fatores de sucesso dos alunos}

Quando questionados sobre as razões que explicam o seu sucesso ou insucesso, salientam a importância do contexto social e familiar: "Não partem todos do mesmo patamar. As questões sociais e familiares são importantes ( nem todos têm a mesma proteção, nem o mesmo ambiente familiar). A tendência é exigir que todos atinjam as mesmas competências ao mesmo tempo e da mesma maneira, é difícil, porque eles não conseguem. Só isso vai diferenciar o sucesso do insucesso" (P5). Consideram também que " depende da valorização dada à pertinência da escola para a consecução dos seus objetivos de vida, não apenas a nível profissional, mas também cultural e de cidadania. Esta valorização parte da cultura familiar ou outras influências pessoais significativas para o aluno. Uma família que encara a escola como um mero instrumento social repressivo, que obriga à frequência de atividades e que a família considera desnecessárias nunca poderá promover o sucesso escolar do aluno"(P6). Outro aspeto pertinente é a auto confiança e imagem da escola: "Mesmo fora da família poderão 
existir atores que influenciem o aluno a considerar a escola de uma forma positiva. Estando este fator assegurado, é necessário também que o aluno tenha, depois, confiança nas suas capacidades e confiança nos agentes educativos” (P1).

\section{Ambiente de aprendizagem}

Os professores consideram que o estudo significa esforço nas tarefas escolares e referem a importância e a valorização do estudo para o futuro. No entanto, "é muito raro os alunos terem motivação intrínseca para aprender. Temos que os fazer ver o que o estudo faz na sua formação" (P6).

A motivação intrínseca e extrínseca impulsiona os alunos para a ação: "Uma percentagem do sucesso deve-se ao empenho e dedicação dos alunos; contudo, existe uma grande percentagem de sucesso que se deve ao cumprimento de orientações superiores que apontam, cada vez mais, para a necessidade de os resultados dos alunos espelharem o sucesso" (P4); "dedicação e empenho do suporte familiar. Nalguns casos esse empenho já foi assumido pessoalmente pelos alunos, porém, em muitos casos, se deixar de existir alguma pressão (que não tem de ser necessariamente repressiva) por parte da família para que o aluno se dedique"(P1).

O Envolvimento dos alunos na sua aprendizagem: "Uma grande parte está envolvida na sua própria aprendizagem. Agora, nós queremos mantê-los quietos, sentados na mesma posição e sempre a ouvir, mas se estiverem envolvidos nas atividades, dialogarem uns com os outros, se mostrarem interesse, à partida já é um passo para o sucesso"( P5); "Os alunos que realmente querem aprender envolvem-se ativamente na sua própria aprendizagem (questionam, pesquisam, procuram saber mais, mobilizam os seus conhecimentos)"(P4).

Perspetiva diferente têm outros professores entrevistados os "alunos muito passivos à espera que o professor faça, são pouco autónomos”(P3); “deve-se ao esforço, empenho, dedicação envolvimento, interação e resiliência dos professores, alunos, diretores de turma, tutores e encarregados de educação"(P2).

\section{Avaliação}

\section{Funções da avaliação}

A avaliação influencia a motivação para o estudo, uma vez que "a atribuição de níveis no final [...]; níveis esses que relevam para a progressão ou não do aluno; é atualmente 
perversa e leva os alunos a compararem-se com outros alunos, de forma indevida, até porque a perceção que se mantém é de que as notas servem para distinguir os bons dos maus alunos. Não há nada de formativo nesta visão das coisas"(P5). Um professor considera que "a avaliação no ensino básico deveria ser absoluta e unicamente formativa: avaliar para melhorar as aprendizagens do aluno e orientar o seu trabalho, bem como o trabalho do professor (P1)". Os professores reconhecem que "a avaliação serve para monitorizar as aprendizagens e dar o feedback aos alunos e aos pais/encarregados de educação acerca das aprendizagens realizadas e dos aspetos a melhorar ou das aprendizagens a adquirir" (P1); (P3); a avaliação tem uma função "reguladora principalmente para o aluno e também para o professor. Para eu verificar se o aluno aprendeu e para o professor verificar se ensinou da melhor maneira"(P6).

\section{Tarefas / critérios de avaliação}

Os professores entrevistados referem que os Instrumentos de avaliação que mais utilizam são "os testes naturalmente, as fichas formativas, questões de aula, relatórios de atividades práticas/experimentais, trabalhos de pesquisa, caderno diário, registos sistemáticos de pontualidade, trabalhos de casa” (P5); (P2);“Os testes são determinados pelo departamento, quer orais quer escritos" (P6); "Utilizo os critérios de avaliação definidos/impostos pela escola. Tal como é imposto pela escola, os testes são o instrumento de avaliação com mais peso"(P1); "Na minha disciplina temos vários instrumentos de diversificação da avaliação: desde fichas de leituras, fichas de gramática, avaliação expressiva, participação trabalhos orais ( se ele se sente a vontade perante os colegas da turma, se o discurso é coerente, se se faz ouvir no fundo da sala), toda a postura e não é só apenas a escrita e avaliação de testes"(P3); “Os instrumentos de avaliação são próprios da especificidade da minha disciplina, que tem um caráter mais prático. Assim, dentro do domínio cognitivo e psicomotor, privilegio o conhecimento dos conteúdos, a criatividade e a sua aplicação em trabalhos individuais, pois têm um peso maior na avaliação"(P4).

\section{Práticas de autoavaliação}

\section{É unanime a opinião dos professores que realizam a autoavaliação formal no final do período}

"Nós devíamos ensinar os nossos alunos a fazer a sua autoavaliação continuamente", pois (os alunos devem autoavaliar-se em situações concretas, caso a caso, e não num 
determinado momento do ano letivo, quando se vão dar as notas" (P2); "Tenho práticas de autoavaliação, no final do período como toda a gente faz. (P5); (P6); No meu caso, os alunos procedem à autoavaliação constantemente, em discussão com a "nota provisória" de cujo valor quantitativo são informados praticamente em todas as aulas. A autoavaliação formal, no final dos períodos, é efetuada, mas é absolutamente irrelevante e improcedente. Para além dos momentos formais de autoavaliação previstos, solicito sempre aos alunos uma reflexão (por escrito, no caderno diário) sobre o trabalho desenvolvido, aspetos que correram menos bem e a melhorar, aquando da entrega das fichas de avaliação (P1); Sempre que converso com os meus alunos acerca dos seus trabalhos, estes fazem uma reflexão oral (autoavaliação) acerca do trabalho realizado e do empenho demonstrados. Além disso, no final de cada período, peço uma autoavaliação mais formal acerca do trabalho realizado ao longo do período (P4); No final de cada período a escola impõe que seja assim, mas quando faço um trabalho de leitura de oralidade eu procuro que façam a sua autoavaliação (P3).

\section{Conclusões}

Conforme fomos revelando, os professores desvendaram as suas perspetivas face ao sucesso e à avaliação, salientando-se um reconhecimento crescente da importância do sucesso escolar de todos os alunos e de todo o processo avaliativo. A avaliação serve para monitorizar as aprendizagens e dar o feedback aos alunos e aos pais/encarregados de educação acerca das aprendizagens realizadas e dos aspetos a melhorar ou das aprendizagens a adquirir.

Para os professores, os alunos partem de patamares diferentes, pelo que uns progridem mais do que outros. Cabe aos professores, na sua prática, selecionar as diversas de tarefas e levar os alunos a participar ativamente, para que a avaliação esteja integrada no processo formativo e se torne possível levar os alunos a estar plenamente envolvidos no seu processo de aprendizagem e ser encorajados a avaliar o seu próprio trabalho.

Os professores entrevistados referem que o sucesso está relacionado com a valorização que os alunos e encarregados de educação atribuem à escola; com a motivação dos alunos para a aprendizagem; com as funções e práticas de avaliação.

Parece, assim, relevante que o currículo seja ajustado às potencialidades e dificuldades dos alunos, com recurso a diferentes níveis de intervenção; que haja uma verdadeira flexibilização curricular que coloque o aluno no centro do processo formativo. É fundamental uma avaliação dialógica, integrada no processo de desenvolvimento curricular e que a sala de 
aula seja um espaço onde se discutam e partilhem procedimentos e estratégias de ensinoaprendizagem-avaliação. Tais dinâmicas conduzirão à reflexividade e à emancipação.

AGRADECIMENTOS: Este estudo teve o financiamento do CIEC (Centro de Investigação em Estudos da Criança), pelo Projeto Estratégico UID/CED/00317/2013, através dos Fundos Nacionais da FCT (Fundação para a Ciência e a Tecnologia), cofinanciado pelo Fundo Europeu de Desenvolvimento Regional (FEDER) através do COMPETE 2020 - Programa Operacional Competitividade e Internacionalização (POCI) com a referência POCI-01-0145FEDER-007562.

\section{REFERÊNCIAS}

ALVES, M. P. Currículo e avaliação: uma perspectiva integrada. Porto: Porto Editora, 2004.

ALVES, M. P; AGUIAR, M.; OLIVEIRA, S. Avaliação no ensino superior: Resultados de uma investigação no domínio das ciências da saúde. In: FERNANDES, D. et al., (Orgs.). Avaliação, ensino e aprendizagem no ensino superior em Portugal e no Brasil: realidades e perspetivas. Volume 2. Lisboa: Educa, 2014. p. 523-562.

BARDIN, L. Análise de conteúdo. Lisboa: Edições 70, 2009.

BELL, J. Como realizar um projeto de investigação. Lisboa: Gradiva, 2002.

BOGDAN, R.; BIKLEN, S. Investigação qualitativa em educação: uma introdução à teoria e aos métodos . Porto: Porto Editora, 1994.

FERNANDES, D. Para uma teoria da avaliação formativa. Revista Portuguesa de Educação, CIEd - Universidade do Minho, v. 19, n. 2, p. 21-50, 2006. Disponível em: www.scielo.oces.mctes.pt/pdf/rpe/v19n2/v19n2a03.pdf. Acesso em: 3 jun. 2013.

LOPES, J.; SILVA, H. Técnicas de avaliação formativa. Lisboa : Edições LIDEL, 2012.

MACHADO, E. Educação que vem entre a performatividade e a esperança. Santo Tirso: whitebooks, 2016.

MARCHESI, A.; GIL, C. Fracasso escolar: uma perspetiva multicultural. Porto Alegre: Artmed, 2004

PINTO, J.; SANTOS, L. Modelos de avaliação das aprendizagens. Lisboa: Universidade Aberta, 2006.

PERRENOUD, P. A pedagogia na escola das diferenças. fragmentos de uma sociologia do fracasso. Porto Alegre: Artmed Editora, 2001. 
Roldão, M.,(2013) Desenvolvimento do currículo e a melhoria de processos e resultados. In: ALVES, M. et al., (Orgs.). Melhorar a Escola, sucesso escolar, disciplina, motivação, direção de escolas e politicas educativas. Porto: Faculdade de Educação e Psicologia da Universidade Católica:, 2013.

SANTOS, T.; ALVES, M. P.Avaliação como controle do estudo: perspetiva dos alunos. In: VEIGA, F. (Coord.) CONGRESSO INTERNACIONAL ENVOLVIMENTO DOS ALUNOS NA ESCOLA: perspetivas da psicologia e educação motivação para o desempenho académico, 2., 2016, Lisboa. Anais [...]. Lisboa: Instituto de Educação da Universidade de Lisboa, 2016. ISBN: 978-989-8753-35-9.

SIMÃO, A. Reforçar o valor regulador formativo e formador da avaliação das aprendizagens. In: ALVES, M. P.; MACHADO, E. A. Avaliação com sentido (s). Contributos e questionamentos. Santo Tirso: De Facto Editores, 2008.

VIEIRA, C. Relação escola-família: uma educação participada. In: PINTO, C. A.; TEIXEIRA, M. (Orgs.). Pais e escola: parceria para o sucesso. Porto: Edições ISET, 2003. p. 291-315.

\section{Como referenciar este artigo}

SANTOS, Teresa de Jesus Correia Paulino dos; ALVES, Maria Palmira. Para uma avaliação emancipadora: a mediação pelo diálogo. Revista Ibero-Americana de Estudos em Educação, Araraquara, v. 15, n. 3, p. 1374-1388, jul./set. 2020. e-ISSN: 1982-5587. DOI: https://doi.org/10.21723/riaee.v15i3.13808

Submetido em: 19/12/2019

Revisões requeridas em: 20/01/2020

Aprovado em: $15 / 02 / 2020$

Publicado em: 20/02/2020 